\title{
Digital Literacies for Language Learning and Teaching: developing a national framework
}

\section{Farr, Fiona ${ }^{a}$ and Murray, Liam ${ }^{b}$}

${ }^{\mathrm{a}}$ Centre for Teaching and Learning, University of Limerick, Ireland, ${ }^{\mathrm{b}}$ School of Modern Languages and Applied Linguistics, University of Limerick, Ireland.

\begin{abstract}
In an Irish national setting, the urgent need to address the national language skills' shortage has been highlighted in numerous arenas, and in the context of the need for a continued economic recovery, language skills and proficiency are essential. Against this backdrop, the national project* reported in this paper aims to develop a digital literacies framework and accompanying on-line interactive resource for language learners and teachers in Irish higher education (HE). Within the scope of this project the target user groups include first year students, study abroad students, and language lecturers. The main research questions for the project are:

- $\quad$ what are the main practical issues that students have when making the transition from secondary to third level language study?

- to what extent are digital literacies part of the curriculum at third level and what gaps do students and lecturers identify in this provision?

- what are the strengths and weaknesses of the emerging digital literacies framework for language learning (as identified through piloting and evaluation) and how do these inform the final design and implementation of the 'digilanguages' platform?
\end{abstract}

Preliminary primary pilot research conducted in 2015 as part of the project identified a number of key areas where online flexible support is best focussed. Based on these findings and international research in the field, the aim of the project is to develop online resources and activities in three broad areas:

\footnotetext{
*This project is funded by the National Forum for the Enhancement of Teaching and Learning, under the auspices of the Higher Education Authority in Ireland.
} 


\section{Digital Literacies for Language Development}

2. Language Learning Strategies and Practices

3. Transitions to Third Level Language Learning Environments

The portal will be freely available, offering a range of OERs and will be scalable for use in other contexts. The contents and activities will afford integration into many programmes currently on offer in Irish HE.

Keywords: Digital literacies; national framework; higher education; language learning; language teaching.

\section{Introduction}

The aim of the project reported in this paper is to develop a national framework for digital literacies for language learning and teaching in an Irish HE context, and to curate and create a wide range of OERs to facilitate its implementation. The overall focus of the recentlyfunded, 18-month project (January 2016-June 2017) is to provide a framework and strategy-oriented on-line resource for language learners and teachers to be fully integrated into third level language programmes in Ireland, including language teacher education programmes for secondary, primary and private sectors. The project team comprises language lecturers and language teacher education lecturers from across a range of geographically diverse locations representing six HE institutions (University of Limerick, National University of Ireland, Galway, Dublin City University, Mary Immaculate College, Limerick, Dublin Institute of Technology, and Limerick Institute of Teachnology). The languages emphasis for the project extends to French, Italian, German, Spanish, Irish and English for Speakers of Other Languages. The main research questions for the project are:

- what are the main practical issues that students have when making the transition from secondary to third level language study?

- $\quad$ to what extent are digital literacies part of the curriculum at third level and what gaps do students and lecturers identify in this provision?

- what are the strengths and weaknesses of the emerging digital literacies framework for language learning (as identified through piloting and evaluation) and how do these inform the final design and implementation of the 'digilanguages' platform?

\section{Background and Context}

During a six-month pilot phase in 2015, the team engaed in a number of fundamental tasks as the foundation for this larger-scale project. Firstly, we defined the problem space, that is, 
the inter-relationship between language teaching and learning, engaging both teachers and learners, paradigm shifts in Applied Linguistics, new developments at national and international level (Erasmus +, virtual mobility, $21^{\text {st }}$ century skills, and graduate attributes). Secondly, we conducted small-scale preliminary primary survey and focus-group research in relation to transition with the three target user groups. 94 first year students responded to the survey and 64 study/work abroad students. In general, significant numbers of the student respondents report not having enough support when making the relevant transitions. The majority of first year $(82.5 \%)$ and study/work aborad students $(91.5 \%)$ indicated the need for online support to assist them with their transition. $91.3 \%$ and $77.8 \%$ respectively said that they would engage with such support. The key practical transition issues as identified by the student user-groups are summarized in Table 1.

Table 1: Top 10 practical issues in relation to transitions: student perceptions

\begin{tabular}{|l|l|l|}
\hline & First Year Students & Study/work Abroad Students \\
\hline 1 & Different teaching approach & Oral skills \\
\hline 2 & Grammar skills & Language skills \\
\hline 3 & Autonomy in $3^{\text {rd }}$ level & $\begin{array}{l}\text { Minimal opportunity to speak/learn the } \\
\text { target language }\end{array}$ \\
\hline 4 & Fast pace in class & Culture \\
\hline 5 & Oral skills & Vocabulary skills \\
\hline 6 & Level of language expected & $\begin{array}{l}\text { Lack of practical information (general } \\
\text { info; accommodation; organisation) }\end{array}$ \\
\hline 7 & Taught through the target language & Grammar skills \\
\hline 8 & Time required and workload & Lack of support \\
\hline 9 & Vocabulary skills & Practising other languages of study \\
\hline 10 & Focus on pronunciation & Making friends \\
\hline
\end{tabular}

Following this, we developed an initial design framework for digital project to assist the three target user groups (first year and study abroad students, and language lecturers) in their engagement with new language pedagogies and digital environments, based on the following core principles (see, Blin et al., 2016):

- An ecological approach to language development and design

- Sustainability

- Participatory design

- Critical awareness of relevant Open Educational Resources

- Localisation. 
Thirdly, we established an international network of partners with relevant expertise in project core areas (see, for example, Farr and Murray, 2016) and languages to inform the direction of the proejct and related content curation and development. Finally, based on primary research results with the various end-user groups (see below), we began the development of a new framework for building digital capacity in language teaching and learning in Irish HEIs (to add discipline-specific granularity to the emerging All-Aboard national framework: http://allaboardhe.org/digital-skills/).

\section{The Framework}

The emerging framework centres on three inter-related areas:

1. Digital literacies for language teaching and learning

2. Digital language teaching and learning strategies and practices with a focus on core language skills

3. Transitioning to digital environments for language teaching and learning.

Each of these three areas will be explored in more detail in the following subsections, which outline the definitions we use, the challenges and gaps that currently exist (as identified in our research to date), and what we aim to do to addresss these gaps. This will be realised in each case through the development of an appropriate framework and the curation and development of OERs as tools to support the implementation of this framework and its integration into third level language curricula. The OERs will be hosted on a portal hosting strategy-focussed activities, which will be piloted and evaluated in the context of selected modules across partner institutions.

\subsection{Digital literacies for language teaching and learning}

We define digital literacy as the individual and social skills needed to effectively interpret, manage, share and create meaning in the growing range of digital communication channels (Dudeney et al., 2014). Based on our preliminary primary research research, the current challenges/gaps for language learners is to acquire and develop digital literacies in a variety of cultural contexts (social, academic, professional) and languages. Our objectives are therefore for learners and teachers to:

- increase awareness of trends in new literacies movement, to enable the development of knowledge and skills for the successful integration and assessment of digital literacies in the language curriculum (teachers) 
○ to display an understanding of digital practices, multiple identities, freedom of expression, social practices in networks (including privacy and safety issues), and the development of critical thinking in different digital genres and across different cultures and Discourse communities.

We aim to achieve this more specifically through the adoption and adaptation of the framework for digital literacies developed by Dudeney et al. (2014), with a particular focus on:

○ Language-related literacies (print, text, hypertext, multi-media, gaming, mobile)

○ Information-related literacies (tagging, searching, reliable resource identification, filtering)

○ Connections-related literacies (digital identity, network and participation in intercultural contexts)

○ (Re-)design literacies (building on and creating new information)

This framework was used to inform the design of a survey, which was distributed in April 2016 to students (330 respondents) and teachers (66 respondents) within the partner institutions, specifically related to digital literacy integration in language curricula. The results to some relevant sections of the survey can be seen in Tables 2 and 3.

Table 2: Digital literacy curriculum integration: student perceptions ( $\%$ responses $^{2}$ )

\begin{tabular}{|l|l|l|l|}
\hline & $\begin{array}{l}\text { Not included and would } \\
\text { not like it to be /would } \\
\text { not like more }\end{array}$ & $\begin{array}{l}\text { Included } \\
\text { adequately }\end{array}$ & $\begin{array}{l}\text { Not included and would like } \\
\text { it to be/would like more }\end{array}$ \\
\hline Print and text & 10.82 & 40.66 & 48.52 \\
\hline $\begin{array}{l}\text { Hypertext and } \\
\text { multimedia }\end{array}$ & 29.5 & 16.72 & 53.78 \\
\hline Gaming & 38.69 & 12.79 & 48.52 \\
\hline Mobile & 20.66 & 14.75 & 64.59 \\
\hline Tagging & 49.83 & 9.5 & 40.67 \\
\hline Searching & 13.11 & 25.25 & 61.64 \\
\hline $\begin{array}{l}\text { Reliable resource } \\
\text { identification }\end{array}$ & 10.82 & 22.62 & 66.56 \\
\hline Filtering and & 20.66 & 15.41 & 63.93 \\
\hline
\end{tabular}

${ }^{2}$ Based on an average of 305 responses to each of these questions across a range of languages being studied 


\begin{tabular}{|l|l|l|l|}
\hline networking & & & \\
\hline Digital identity & 34.48 & 14.10 & 51.42 \\
\hline $\begin{array}{l}\text { Intercultural } \\
\text { networking and } \\
\text { participation }\end{array}$ & 27.54 & 11.8 & 60.66 \\
\hline Building on & 15.08 & 26.88 & 58.04 \\
\hline
\end{tabular}

In general the majority of students would like to see the inclusion or further inclion of most of the items from the framework. The main exception is tagging, with print and text, and gamining both coming in just under majority at $48.52 \%$. This clearly identifies a want and a need on the part of students to increase their engagement with such digital literacies. Lecturers were asked a related question about how important $(1=$ least important, $5=$ most important) they felt it was for their students to learn these literacies as part of their programme of study and the results can be found in Table 3.

Table 3: Digital literacy curriculum integration: lecturer perceptions ( $\%$ responses $^{3}$ )

\begin{tabular}{|l|l|l|l|l|l|}
\hline & $\mathbf{1}$ & $\mathbf{2}$ & $\mathbf{3}$ & $\mathbf{4}$ & $\mathbf{5}$ \\
\hline Print and text & 2.13 & 12.77 & 27.66 & 36.17 & 21.28 \\
\hline $\begin{array}{l}\text { Hypertext and } \\
\text { multimedia }\end{array}$ & 2.08 & 16.67 & 45.83 & 25 & 10.42 \\
\hline Gaming & 21.28 & 17.02 & 29.79 & 23.4 & 8.51 \\
\hline Mobile & 6.38 & 6.38 & 29.79 & 42.55 & 14.89 \\
\hline Tagging & 41.86 & 13.95 & 34.88 & 4.65 & 4.65 \\
\hline Searching & 2.13 & 6.38 & 12.77 & 44.68 & 34.04 \\
\hline $\begin{array}{l}\text { Reliable resource } \\
\text { identification }\end{array}$ & 0 & 0 & 27.66 & 21.28 & 51.05 \\
\hline $\begin{array}{l}\text { Filtering and } \\
\text { networking }\end{array}$ & 6.38 & 14.89 & 29.79 & 36.17 & 12.77 \\
\hline Digital identity & 8.51 & 17.02 & 34.04 & 31.91 & 8.51 \\
\hline $\begin{array}{l}\text { Intercultural } \\
\text { networking and } \\
\text { participation }\end{array}$ & 13.33 & 17.78 & 28.89 & 28.89 & 11.11 \\
\hline $\begin{array}{l}\text { Building on and } \\
\text { creating new } \\
\text { information }\end{array}$ & 8.89 & 6.67 & 31.11 & 35.56 & 17.78 \\
\hline
\end{tabular}

3 Based on an average of 47 responses to each of these questions 
The lecturer responses to this part of the survey very much mirror the student perceptions and opinions. The vast majority of literacies are considered important or very important with the exception of gaming and tagging. These results indetify the significance lecturers afford to these digital literacies in a language learning context.

\subsection{Digital language teaching and learning strategies and practices}

The second part of the framework includes a re-definition of core language skills in the $21^{\text {st }}$ century, recognising important paradigm shifts (with references to multiple literacies, and designs for teaching and learning). The identified need here is for new language pedagogies appropriate for deployment in technology rich learning environments and Computer Supported Collaborative (Language) Learning environments (Blin and Jalkahen, 2014), which focus on new strategies and competencies for consolidating and practising written and spoken skills online. This will enable:

- the practice of language skills, using strategy-focussed entry points to the portal

○ the development of opportunities for new online language use and practice (telecollaboration, journaling (Gabaudan, forthcoming 2016), virtual worlds and gaming (Peterson, 2013), synchronous and asynchronous communication, corpus linguistics (O'Keeffe et al., 2007), the creation of digital and multimodal objects)

- language teachers and learners to appropriately use electronic resources to augment their linguistic knowledge (use of online dictionaries, corpora, machine translation, sub-titling, captioning/annotating).

\subsection{Transitioning to digital environments for language teaching and learning}

Finally, the framework carefully addresses lifelong language learning, learner autonomy, metacognition, computer supported collaborative language learning, and learning how to cope with technology. Our research shoes that there are difficulties in the transition from face-to-face to online environments, from teacher-led pedagogies (for example at secondary school) to self-directed learning (in HE), from digital vernaculars to formal learning settings, from virtual learning environment (VLE) to personal learning (PLE), from independent to computer supported collaborative language learning. The objective is therefore to provide resources to enable language learners to become lifelong learners of languages, toe enable language teachers and learners to create and maintain PLNs/PLEs and to develop appropriate strategies for the successful integration of technology for language acquisition. This involves the adaption and development of online tools for assisting language learners in assessing their language learning strategies and styles, in recognising and realising the affordances of digital tools in different languages and cultural contexts, in 
building and maintaining PLNs and PLEs, and in creating an e-portfolio to showcase learning experience and outcomes.

\section{Discussion}

The framework outlined in the previous sections is based on preliminary research conducted as part of the pilot phase of this project, plus on-going research with the targetuser groups (only some of which has been reported here). This conference paper outlines the development of the framework and presents it in detail as a set of skills, strategies and conceptually congruent pathways, which will be completed at the end of the first six-month project period of the project (June, 2016). The iterative processes involved in this development (including consultation with key stakeholders, further primary research in the form of national surveys and a number of focus-group discussions) are presented, along with key results. The beginning of the development of the OERs in each of the three key areas included in the digital literacies for language learning and teaching framework (digilanguages) are presented and discussed, along with a detailed plan for pilot and evaluation phases. The project, its outcomes, and their implementation in HE language curricula will represent a significant and unique step forward for any European country in this way.

\section{References}

Dudeney, G., Hockly, N. and Pegrum, M. (2014. Digital Literacies. Harlow: Pearson.

Blin, F. and Jalkahen, J. (2014). Designing for language learning: agency and languaging in hybrid environments. Journal of Applied Language Studies, 8(1), 147-170.

Blin, F., Jalkanen, J. and Taalas, P. (2016). 'Sustainable CALL development', in Farr, F. and Murray, L., (eds.), The Routledge Handbook of Language Learning and Technology, London and New York: Routledge, 223-238.

Farr, F. and Murray, L., eds. (2016). Routledge Handbook of Language Learning and Technology. London and New York: Routledge.

Gabaudan, O. (forthcoming 2016) 'Too soon to fly the coop? Online journaling to support students' learning during their Erasmus study visit' ReCall.

O'Keeffe, A., McCarthy, M. and Carter, R. (2007). From Corpus to Classroom, Cambridge: Cambridge University Press.

Peterson, M. (2013). Computer Games and Language Learning, London: Palgrave Macmillan. 